\title{
Audiological and Vestibular Functions in Patients With Lateral Semicircular Canal Dysplasia and Aplasia
}

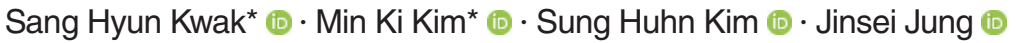 \\ Department of Otorhinolaryngology, Yonsei University College of Medicine, Seoul, Korea
}

Objectives. The aim of the present study was to evaluate audiologic and vestibular functions in patients with lateral semicircular canal (LSCC) dysplasia/aplasia.

Methods. We conducted a retrospective study of a patients with LSCC dysplasia and aplasia at tertiary referral center. The subjects included 15 patients with LSCC dysplasia or aplasia, with or without combined inner ear anomalies. Medical history, temporal bone computed tomography scans, pure-tone audiograms, and vestibular function test results were analyzed.

Results. LSCC anomaly was identified in 15 patients (20 ears). Nine patients had unilateral LSCC dysplasia only and showed a mean pure-tone average of $45.5 \pm 28.7 \mathrm{~dB}$, while three patients $(33.3 \%)$ among them had normal hearing. Six patients had bilateral LSCC dysplasia/aplasia combined with other inner ear anomalies and profound bilateral hearing loss. Notably, only four out of 15 patients $(26.7 \%)$ had dizziness symptoms. On caloric test, patients with isolated LSCC dysplasia showed a $51.8 \% \pm 29.3 \%$ level of canal paresis (eight out of nine patients showed anomalies), whereas patients with bilateral LSCC dysplasia/aplasia presented bilateral vestibular loss. One patient with isolated LSCC underwent video-head impulse test; horizontal canal gain decreased to 0.62 (17\% asymmetry) and anterior canal gain was 0.45 (52.6\% asymmetry), whereas posterior canal gain was normal.

Conclusion. Bilateral LSCC dysplasia/aplasia is comorbid with other inner ear anomalies and presents as profound bilateral hearing loss and vestibulopathy. In contrast, isolated unilateral LSCC dysplasia presents as ipsilateral horizontal canal paresis. Hearing function in isolated LSCC dysplasia is usually, but not always, impaired with varying severity.

Keywords. Lateral Semicircular Canal Malformation; Semicircular Canal; Bilateral Vestibulopathy; Deafness

\section{INTRODUCTION}

Hearing loss is one of the most common sensorial disorders in children, with incidence rates of one to three per 1,000 newborns [1]. The etiology of hearing loss varies, but at least half of

- Received July 11, 2019

Revised October 8, 2019

Accepted October 14, 2019

- Corresponding author: Jinsei Jung

Department of Otorhinolaryngology, Yonsei University College of Medicine,

50-1 Yonsei-ro, Seodaemun-gu, Seoul 03722, Korea

Tel: +82-2-2228-3626, Fax: +82-2-393-0580

E-mail: jsjung@yuhs.ac

*These authors contributed equally to this article. hearing loss cases are due to genetic factors, such as hereditary disorders. About $20 \%$ of hearing loss cases in children are associated with inner ear malformations, which may cause profound sensorineural hearing loss [2]. Unsuspected congenital malformations are found in approximately $2.3 \%$ of inner ear radiologic studies [3]. Inner ear malformations can result from embryologic arrest, possibly influenced by genetic factors [4].

Lateral semicircular canal (LSCC) malformation is one of the most common radiological anomalies of the bony labyrinth [5]. During the 5th week of embryonic development, superior semicircular canal is the first semicircular canal to develop, followed by posterior semicircular canal. LSCC is the last to develop, and thus may present as an isolated developmental abnormality. The

Copyright (C) 2020 by Korean Society of Otorhinolaryngology-Head and Neck Surgery.

This is an open-access article distributed under the terms of the Creative Commons Attribution Non-Commercial License (https://creativecommons.org/licenses/by-nc/4.0)

which permits unrestricted non-commercial use, distribution, and reproduction in any medium, provided the original work is properly cited. 
most common form of LSCC anomaly is hypoplasia such as dilatation, as well as shortened or narrowed LSCC [5]. Aplasia, defined as the absence of LSCC, is the most severe form of anomaly and may manifest as part of several broader syndromes, such as CHARGE syndrome [6]. In the literature, Johnson and Lalwani [7] reported that there are diverse types of hearing loss associated with LSCC malformation. The majority of patients with LSCC malformation have sensorineural hearing loss, whereas some have pure or mixed conductive hearing loss. Nevertheless, there have been few reports on vestibular manifestations and performance on audiologic tests in LSCC malformation. Therefore, this study aimed to evaluate audiologic as well as vestibular functions in patients with LSCC malformation.

\section{MATERIALS AND METHODS}

We conducted a retrospective study of patients with LSCC dysplasia at Severance Hospital of Yonsei University Health System, one of the largest tertiary hospitals in Seoul, South Korea. From 2007 to 2017, a total of 15 patients were retrospectively enrolled through the Department of Otolaryngology. Medical histories were reviewed for audiologic symptoms and relevant findings including the etiology of hearing loss, treatment of hearing loss, and accompanying vestibular symptoms. All patients underwent temporal bone computed tomography (CT) scans to evaluate mostly hearing loss, followed by dizziness and chronic otitis media. The enrolled subjects were diagnosed with LSCC dysplasia or aplasia, with or without combined inner ear anomalies, as confirmed by temporal bone CT scans by a radiologist specialized in head and neck section. After that, final diagnosis was made by ENT specialists (Fig. 1). For audiologic assessment, a four-frequency pure-tone average $(0.5,1,2$, and $4 \mathrm{kHz})$ was obtained from pure-tone audiogram. Vestibular functions were assessed by caloric test and video-assisted head impulse test (vHIT). We calculated canal paresis using caloric test according to Jongkee's formula. The vHIT of LSCC was analyzed by gain value and the presence of catch-up saccade. This study was approved by Institutional Review Board of Severance Hospital, Yonsei University Health System (IRB No. 4-2015-0659).

\section{\begin{tabular}{l|l|l|l|l|l|l|l|l|l} 
H & I & G & H & L & I & G & H & T & S
\end{tabular}}

- Lateral semicircular canal (LSCC) malformation is one of the most common radiologic anomalies of the bony labyrinth.

- Usually bilateral LSCC dysplasia and aplasia may result in profound bilateral hearing loss, due to combined other inner ear anomalies.

- Isolated LSCC dysplasia is associated with varying degrees of hearing loss and vestibular symptoms.
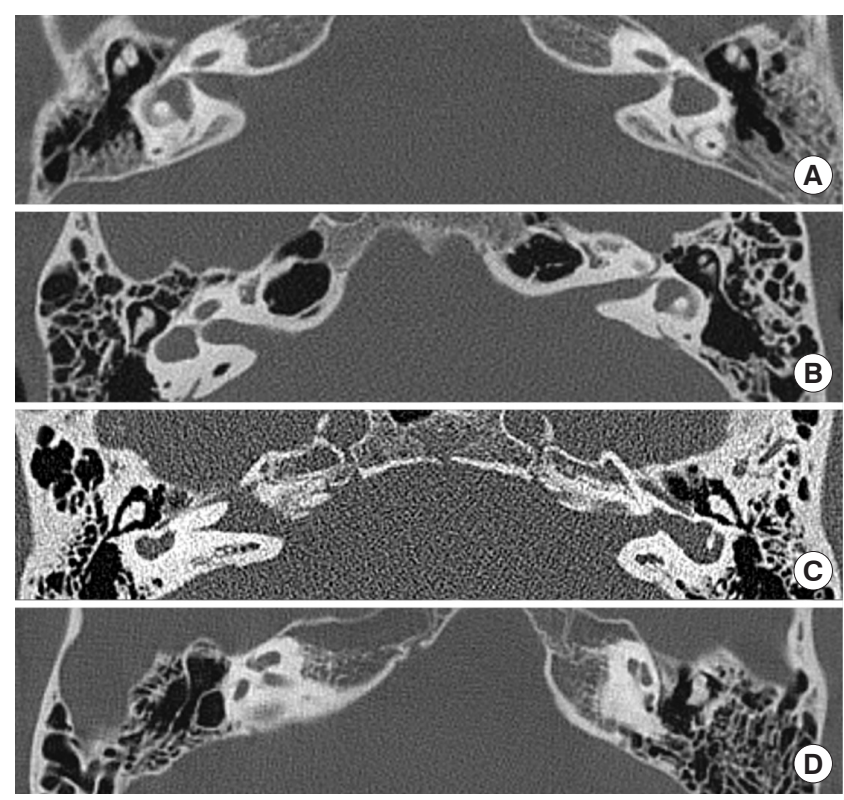

Fig. 1. (A) High-resolution temporal bone computed tomography scan of a patient with left unilateral lateral semicircular canal (LSCC) dysplasia and the absence of central bony island of LSCC. (B) Example of a right unilateral LSCC dysplasia case. (C) Example of a bilateral LSCC dysplasia case with comorbid cochlea aplasia. (D) Bilateral LSCC dysplasia with combined unilateral cochlea hypoplasia on the right side.

Table 1. Demographic characteristics of the patients

\begin{tabular}{lc}
\hline Characteristics & Value $(\mathrm{n}=15)$ \\
\hline Age $(\mathrm{yr})$ & $34.8 \pm 20.8$ \\
Sex & \\
$\quad$ Male & $8(53.3)$ \\
Female & $7(46.7)$ \\
Dizziness symptom & $4(26.7)$ \\
Prevalence & \\
Characteristics & $2(13.3)$ \\
$\quad$ Spinning sensation & $2(13.3)$ \\
$\quad$ Gait imbalance & $37.8 \pm 21.5$ \\
Age at onset (yr) & \\
Site of LSCC dysplasia & $9(60)$ \\
Unilateral & $6(40)$ \\
Bilateral
\end{tabular}

Values are presented as mean \pm standard deviation or number (\%). LSCC, lateral semicircular canal.

\section{RESULTS}

\section{Patient characteristics}

Fifteen patients (20 affected ears in total) were identified, and their mean age was 34.8 years (Tables 1 and 2). Eight patients were male and seven patients were female. These nine cases were of unilateral LSCC dysplasia (Fig. 1A, B), whereas six patients showed bilateral LSCC dysplasia (Fig. 1C, D). Four out of six 
Table 2. Clinical characteristics of LSCC dysplasia/aplasia

\begin{tabular}{|c|c|c|c|c|c|c|c|c|c|}
\hline $\begin{array}{c}\text { Patient } \\
\text { No. }\end{array}$ & $\begin{array}{l}\text { Age } \\
(y r)\end{array}$ & Sex & $\begin{array}{c}\text { Site of } \\
\text { LSCC lesion }\end{array}$ & $\begin{array}{l}\text { Onset age of } \\
\text { hearing loss } \\
(y r)\end{array}$ & $\begin{array}{l}\mathrm{PTA}_{4} \\
(\mathrm{~dB}), \\
\text { right }\end{array}$ & $\begin{array}{l}\mathrm{PTA}_{4} \\
\text { (dB), } \\
\text { left }\end{array}$ & Combined inner ear anomaly & $\begin{array}{l}\text { Cochlear } \\
\text { implantion }\end{array}$ & $\begin{array}{c}\text { Postoperative } \\
\text { CAP score } \\
\text { (1 yr) }\end{array}$ \\
\hline 1 & 20 & $\mathrm{~F}$ & Right (dysplasia) & & 28 & 29 & No & No & \\
\hline 2 & 74 & $\mathrm{~F}$ & Right (dysplasia) & 34 & 57 & 13 & No & No & \\
\hline 3 & 44 & M & Right (dysplasia) & & 10 & 12 & No & No & \\
\hline 4 & 75 & M & Right (dysplasia) & 55 & 79 & 33 & No & No & \\
\hline 5 & 58 & M & Right (dysplasia) & 58 & 78 & 20 & No & No & \\
\hline 6 & 6 & $\mathrm{~F}$ & Left (dysplasia) & & 17 & 18 & No & No & \\
\hline 7 & 43 & $\mathrm{~F}$ & Left (dysplasia) & & 8 & 52 & No & No & \\
\hline 8 & 15 & M & Left (dysplasia) & & 10 & 13 & No & No & \\
\hline 9 & 27 & M & Left (dysplasia) & 24 & 35 & 75 & No & No & \\
\hline 10 & 47 & M & Both (dysplasia) & 12 & 116 & 118 & No & Left & $4(3 \mathrm{mo})$ \\
\hline 11 & 27 & $\mathrm{~F}$ & Both (dysplasia) & Congenital & 120 & 120 & PSCC dysplasia (both) & Left & 5 \\
\hline 12 & 32 & $\mathrm{~F}$ & Both (aplasia) & Congenital & 120 & 75 & ASCC/PSCC aplasia and incomplete partition I (right) & Left & 7 \\
\hline 13 & 36 & $\mathrm{~F}$ & Both (aplasia) & 14 & 92 & 58 & ASCC/PSCC aplasia and cochlea hypoplasia III (right) & No & \\
\hline 14 & 19 & M & Both (aplasia) & Congenital & 115 & 115 & ASCC/PSCC aplasia and IAC stenosis (both) & Right & 5 \\
\hline 15 & 13 & M & Both (aplasia) & Congenital & 120 & 120 & ASCC/PSCC aplasia and cochlea aplasia (both) & Left & 3 \\
\hline
\end{tabular}

LSCC, lateral semicircular canal; PTA 4 , the average threshold of 0.5, 0.1, 2, and $4 \mathrm{kHz}$; CAP, Categorized of Auditory Performance; F, female; M, male; PSCC, posterior semicircular canal; ASCC, anterior semicircular canal; IAC, internal auditory canal.

Table 3. Cochlear implantation of lateral semicircular canal dysplasia/aplasia patients

\begin{tabular}{|c|c|c|c|c|c|c|c|c|c|c|}
\hline $\begin{array}{l}\text { Patient } \\
\text { No. }\end{array}$ & $\begin{array}{l}\text { Age } \\
(\mathrm{yr})\end{array}$ & Sex & $\begin{array}{l}\text { Onset age of } \\
\text { hearing loss } \\
(y r)\end{array}$ & $\begin{array}{l}\mathrm{PTA}_{4} \\
(\mathrm{~dB}), \\
\text { right }\end{array}$ & $\begin{array}{c}\mathrm{PTA}_{4} \\
(\mathrm{~dB}), \\
\text { left }\end{array}$ & $\begin{array}{c}\text { Combined } \\
\text { inner ear anomaly }\end{array}$ & $\begin{array}{l}\text { Cochlear } \\
\text { implantation }\end{array}$ & $\begin{array}{c}\text { Postoperative } \\
\mathrm{PTA}_{4}(\mathrm{~dB})\end{array}$ & $\begin{array}{c}\text { Postoperative } \\
\text { CAP score } \\
(1 \mathrm{yr})\end{array}$ & $\begin{array}{c}\text { Postoperative } \\
\text { complication }\end{array}$ \\
\hline 10 & 47 & M & 12 & 116 & 118 & None & Left & 26 & $4(3 \mathrm{mo})$ & None \\
\hline 11 & 27 & $\mathrm{~F}$ & Congenital & 120 & 120 & PSCC dysplasia (both) & Left & 27 & 5 & None \\
\hline 12 & 32 & $\mathrm{~F}$ & Congenital & 120 & 75 & $\begin{array}{l}\text { ASCC/PSCC aplasia and } \\
\text { incomplete partition I (right) }\end{array}$ & Left & 21 & 7 & None \\
\hline 14 & 19 & M & Congenital & 115 & 115 & $\begin{array}{l}\text { ASCC/PSCC aplasia and } \\
\text { IAC stenosis (both) }\end{array}$ & Right & 38 & 5 & $\begin{array}{l}\text { Facial } \\
\text { twitching }\end{array}$ \\
\hline 15 & 13 & M & Congenital & 120 & 120 & $\begin{array}{c}\text { ASCC/PSCC aplasia and } \\
\text { cochlea aplasia (both) }\end{array}$ & Left & 48 & 3 & None \\
\hline
\end{tabular}

$\mathrm{PTA}_{4}$, the average threshold of $0.5,0.1,2$, and $4 \mathrm{kHz}$; CAP, Categorized of Auditory Performance; M, male; F, female; PSCC, posterior semicircular canal; ASCC, anterior semicircular canal; IAC, internal auditory canal.

patients with bilateral LSCC showed LSCC aplasia, combined with cochlear anomalies. However, one patient with bilateral LSCC dysplasia showed normal cochlear anatomy, although the patient had acquired sensorineural hearing loss on both ears.

\section{Audiologic evaluation}

In the unilateral LSCC dysplasia group, the mean average threshold of $0.5,1,2$, and $4 \mathrm{kHz}\left(\mathrm{PTA}_{4}\right)$ was $45.5 \mathrm{~dB}$, while three patients had normal hearing levels. In contrast, six patients with bilateral LSCC anomalies had profound hearing loss. Eventually, five patients underwent cochlear implantation surgery (Table 3). Four patients had favorable outcomes after cochlear implantation, as defined by a postoperative Categorized of Auditory Performance (CAP) score of more than 4 points. One patient with comorbid cochlea aplasia had a relatively poor outcome after surgery. No patient complained of dizziness after surgery. One patient showed facial twitching after activation of cochlear implant, which was resolved by decreasing the dynamic range of the offending electrodes.

\section{Vestibular evaluation}

Four out of 15 patients had dizziness symptoms, which were characterized as spinning sensation and/or gait disturbance. Interestingly, dizziness patients all belonged to unilateral LSCC dysplasia groups (Table 4). Two of them described feeling of spinning sensation, whereas the other two patients complained of gait imbalance; their mean age at onset was 37.8 years. All patients underwent caloric stimulation test, and two patients underwent video head impulse test. Only two patients showed normal canal paresis value on caloric testing; two patients with unilateral LSCC dysplasia showed ipsilateral complete canal paresis. Mean canal paresis was $51.8 \%$. In one patient with isolated unilateral LSCC dysplasia (patient 5), horizontal canal gain decreased to 0.62 (17\% asymmetry) and anterior canal gain 
Table 4. Vestibular functions of LSCC dysplasia/aplasia

\begin{tabular}{|c|c|c|c|c|c|c|c|c|c|c|c|}
\hline $\begin{array}{l}\text { Patient } \\
\text { No. }\end{array}$ & $\begin{array}{c}\text { Site of LSCC } \\
\text { lesion }\end{array}$ & $\begin{array}{l}\text { Dizziness } \\
\text { symptom }\end{array}$ & $\begin{array}{c}\text { Onset age } \\
\text { of dizziness } \\
(\mathrm{yr})\end{array}$ & $\begin{array}{l}\text { Dizziness } \\
\text { feature }\end{array}$ & $\begin{array}{l}\text { Combined inner ear } \\
\text { anomaly }\end{array}$ & $\begin{array}{l}\text { Side } \\
\text { of } \\
\text { CP }\end{array}$ & $\begin{array}{l}\mathrm{CP} \\
(\%)\end{array}$ & $\begin{array}{l}\text { Horizontal } \\
\text { vHIT gain } \\
\text { (Rt/Lt) }\end{array}$ & $\begin{array}{l}\text { Anterior } \\
\text { vHIT gain }{ }^{a)} \\
(R t / L t)\end{array}$ & $\begin{array}{l}\text { Posterior } \\
\text { vHIT gain }{ }^{a)} \\
\text { (Rt/Lt) }\end{array}$ & $\begin{array}{c}\text { cVEMP } \\
\text { amplitude } \\
\text { (asymmetry) }\end{array}$ \\
\hline 1 & Rt (dysplasia) & No & & & No & Rt & 36 & & & & \\
\hline 2 & Rt (dysplasia) & Yes & 54 & $\begin{array}{l}\text { Gait } \\
\text { imbalance }\end{array}$ & No & Rt & 100 & & & & $\begin{array}{l}\text { Right } \\
(36.8 \%)\end{array}$ \\
\hline 3 & Rt (dysplasia) & No & & & No & Rt & 59 & & & & \\
\hline 4 & Rt (dysplasia) & No & & & No & Rt & 46 & & & & \\
\hline 5 & Rt (dysplasia) & Yes & 58 & $\begin{array}{l}\text { Spinning } \\
\text { sense }\end{array}$ & No & Rt & 25 & $0.62^{\mathrm{a})} / 0.94$ & $0.45^{\mathrm{a})} / 0.99$ & $0.84 / 0.95$ & \\
\hline 6 & Lt (dysplasia) & No & & & No & $\mathrm{Lt}$ & 36 & & & & \\
\hline 7 & Lt (dysplasia) & No & & & No & Rt & 24 & & & & $\begin{array}{l}\text { Right } \\
(40.6 \%)\end{array}$ \\
\hline 8 & Lt (dysplasia) & Yes & 15 & $\begin{array}{l}\text { Spinning } \\
\text { sense }\end{array}$ & No & $\mathrm{Lt}$ & 100 & & & & \\
\hline 9 & Lt (dysplasia) & Yes & 24 & $\begin{array}{l}\text { Gait } \\
\text { imbalance }\end{array}$ & No & $\mathrm{Lt}$ & 40 & & & & \\
\hline 10 & B (dysplasia) & No & & & No & B & 100 & & & & \\
\hline 11 & B (dysplasia) & No & & & PSCC dysplasia (both) & B & 100 & $0.51^{\mathrm{a}} / 0.54^{\mathrm{a})}$ & $0.39^{\mathrm{a}} / 0.49^{\mathrm{a})}$ & $0.36^{a} / 0.26^{a)}$ & \\
\hline 12 & B (aplasia) & No & & & $\begin{array}{l}\text { ASCC/PSCC aplasia and } \\
\text { incomplete partition I } \\
\text { (right) }\end{array}$ & B & 100 & & & & \\
\hline 13 & B (aplasia) & No & & & $\begin{array}{l}\text { ASCC/PSCC aplasia and } \\
\text { cochlea hypoplasia III } \\
\text { (right) }\end{array}$ & B & 100 & & & & \\
\hline 14 & B (aplasia) & No & & & $\begin{array}{l}\text { ASCC/PSCC aplasia and } \\
\text { IAC stenosis (both) }\end{array}$ & B & 100 & & & & \\
\hline 15 & B (aplasia) & No & & & $\begin{array}{c}\text { ASCC/PSCC aplasia and } \\
\text { cochlea aplasia (both) }\end{array}$ & B & 100 & & & & \\
\hline
\end{tabular}

Canal paresis $100 \%$ in bilateral anomaly patients group means no response in both ears.

LSCC, lateral semicircular canal; CP, canal paresis according to Jongkee's formula; vHIT, video-assisted head impulse test; Rt, right; Lt, left; cVEMP, cervical vestibular-evoked myogenic potential; B, both; PSCC, posterior semicircular canal; ASCC, anterior semicircular canal; IAC, internal auditory canal.

a) VHIT LSCC gain value and presence of catch-up saccade at the side of CP.

was 0.45 (52.6\% asymmetry), whereas posterior canal gain was normal on vHIT (Fig. 2). These results imply that the end organs innervated by superior vestibular nerve are functionally impaired in isolated LSCC dysplasia.

\section{DISCUSSION}

In this study, we observed that bilateral LSCC dysplasia or aplasia was usually combined with other inner ear anomalies, resulting in profound bilateral hearing loss and vestibulopathy. Only one patient with bilateral LSCC anomalies showed asymmetric hearing loss. Temporal bone CT of this patient showed more severe combined anomalies on the right side, consistent with the hearing threshold being better on the left side. Therefore, LSCC anomalies combined with other inner ear anomalies resulted in severe hearing loss, in line with previous reports $[8,9]$.

A previous temporal bone anatomy study reported that LSCC anomalies are the most common anomalies of the inner ear $[5,10]$. LSCC anomalies can be combined with other inner ear anomalies, including those of the cochlea, vestibule, and vestibular aqueduct, depending on which developmental stages of the inner ear are impacted [11]. The semicircular canal develops at embryonic weeks 4 to 7 , and early developmental arrest results in deformity of the entire semicircular canal and other structures of the inner ear [12]. Ossification of the labyrinth is completed by the 23rd week, and LSCC is the last of the semicircular canals to complete ossification. Disturbance in ossification may result in LSCC dysplasia, such as lack of a central ossified bony island and a short LSCC complex [13,14].

Our study showed various degrees of hearing loss, with some patients with unilateral LSCC even displaying normal hearing levels. Yamashita et al. [13] reported that there was no correlation with hearing loss in isolated dysplasia of patients with LSCC. Nevertheless, Dallan et al. [15] reported similar results in bilateral LSCC dysplasia. These findings suggest that hearing loss in LSCC dysplasia is likely correlated with anomalous membranous labyrinth development, which we could not find on radiologic examination.

Yu et al. [4] investigated the molecular genetic background of 


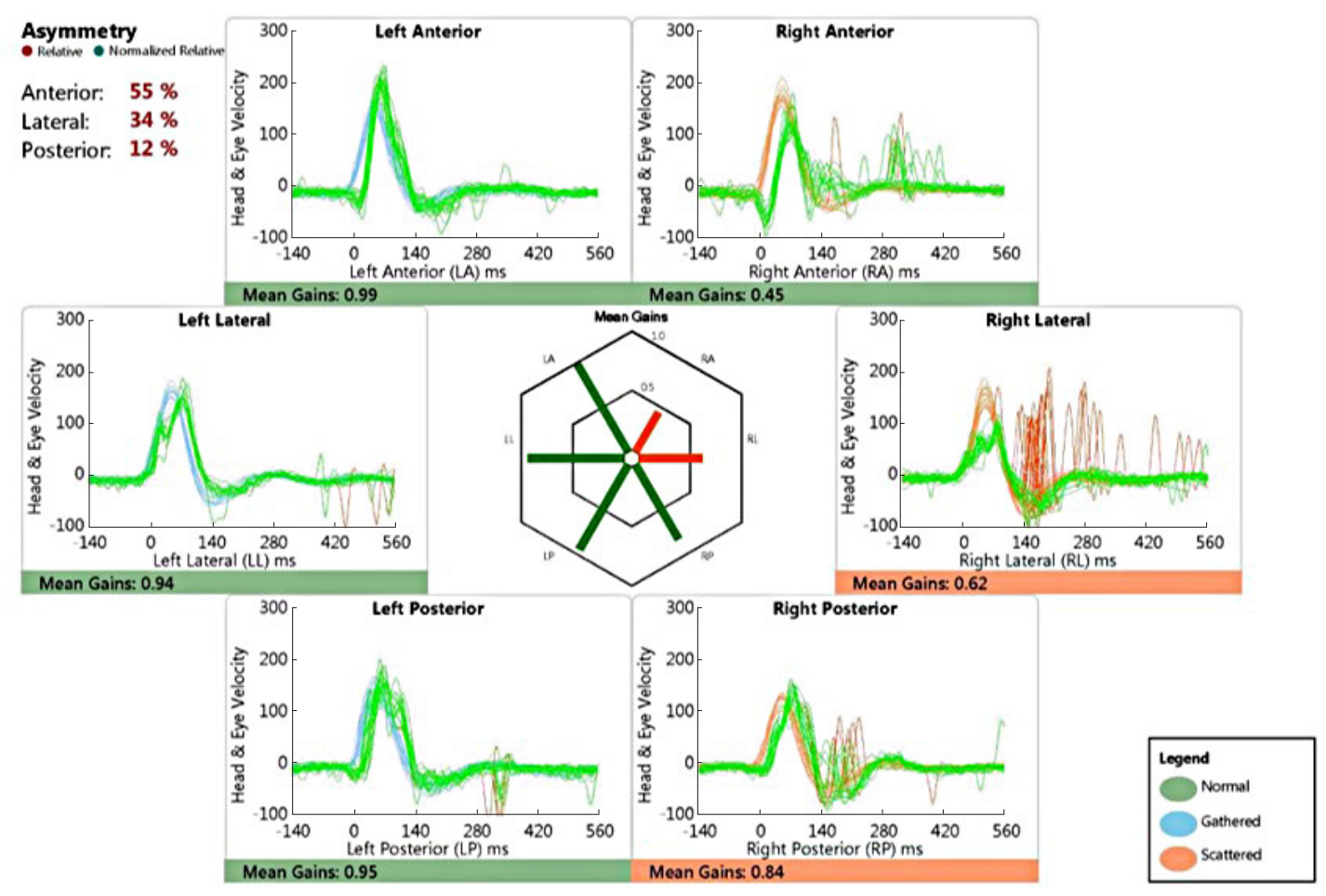

Fig. 2. The results of video head impulse test showing decreased gain of the right lateral canal and anterior canal, with dominant catch-up saccade movement on the lateral canal. However, the gain of the posterior canal was relatively normal.

semicircular canal anomalies, and found mutations across a number of genes that resulted in various inner ear defects. During embryonic development, genetic mutations can alter the regulation of transcription factors that play critical roles in the differentiation of specific organs. In addition, Hadrys et al. [16] reported on a knockout mouse model of LSCC malformation in which $N k \times 5.1$, a transcription factor expressed in the presumptive area of the semicircular canal, was deleted. These reports suggest that the pathophysiology of inner ear anomalies may be attributable to genetic defects, and thus genetic counseling should be considered, although the genetic causes of LSCC remain elusive.

The current study suggests a lack of correlation between vestibular function and hearing loss. Only four patients complained about dizziness symptoms, and the onset time of dizziness varied. Different onset times of dizziness symptoms may be attributable to the incomplete compensation by central nerve system and insufficient residual balance function of peripheral vestibular system. Patients with LSCC anomalies are considered to have a small balance capacity; therefore, they are more vulnerable to be affected by uncompenation caused by various origins such as upper respiratory infection infection, malnutrition, stressful condition, or vestibular neuritis.

The results of vestibular examination quite varied according to different patients. Despite the presence of dizziness symptoms, the abnormal value of canal paresis was given on the same side in most unilateral LSCC dysplasia patients. These results indicate that membranous labyrinth had dysplasia, along with bony labyrinth dysplasia, in our patients. In addition, caloric tests were mostly affected by convection effect of endolymph. LSCC dysplasia may change the area ratio in comparison to the normal side, causing canal paresis. McGarvie et al. [17] explained the abnomal canal paresis in caloric test may have resulted from theoretically dissipated hydrostatic pressure in dilated membranous labyrinth in Meniere disease. This theoretical dissipation model can explain our abnormal caloric results on the same side of the affected ear. In contrast, normal values of caloric test in patients with unilateral LSCC dysplasia may infer that anomalies of bony labyrinth are not sufficiently correlated with abnormal vestibular function [18]. As for the results in vHIT, one patient showed normal posterior semicircular canal gain, in addition to abnormal gain in both lateral and superior semicircular canal. This result in vHIT shows impaired superior vestibular nerve in isolated LSCC dysplasia. Superior vestibular nerve innervates to utricle, as well as lateral and superior semicircular canals. Abnormal vHIT and LSCC anomaly can be further explained by the loss of type 1 hair cell. Type 1 hair cells are associated with high acceleration stimuli, which are well correlated with vHIT test. Type 1 hair cells are more abundantly found in crista ampullaris, and LSCC dysplasia might lead to loss of type 1 hair cells and subsequently cause less gain of vHIT [19].

In conclusion, our study showed varying clinical characteris- 
tics of LSCC anomalies. Bilateral LSCC dysplasia/aplasia is usually combined with other inner ear anomalies, which may result in profound bilateral hearing loss. However, isolated LSCC dysplasia was associated with varying degrees of hearing loss, and vestibular symptoms did not always accompany LSCC anomalies in our patients.

\section{CONFLICT OF INTEREST}

No potential conflict of interest relevant to this article was reported.

\section{ACKNOWLEDGMENTS}

This research was supported by the Research Program through the National Research Foundation of Korea (NRF) funded by the Korea government (2017R1D1A1B03030046).

\section{ORCID}

Sang Hyun Kwak https://orcid.org/0000-0002-2827-8456

Min Ki Kim https://orcid.org/0000-0002-3047-2127

Sung Huhn Kim https://orcid.org/0000-0003-4408-3066

Jinsei Jung https://orcid.org/0000-0003-1906-6969

\section{AUTHOR CONTRIBUTIONS}

Conceptualization: JJ. Data curation: MKK. Formal analysis: MKK. Funding acquisition: JJ. Methodology: SHK. Project administration: JJ. Visualization: JJ. Writing-original draft: SHK. Writing-review \& editing: SHK, JJ.

\section{REFERENCES}

1. Korver AM, Smith RJ, Van Camp G, Schleiss MR, Bitner-Glindzicz MA, Lustig LR, et al. Congenital hearing loss. Nat Rev Dis Primers. 2017 Jan;3:16094.

2. Jensen J. Congenital anomalies of the inner ear. Radiol Clin North Am. 1974 Dec;12(3):473-82.
3. Casselman JW, Offeciers EF, De Foer B, Govaerts P, Kuhweide R, Somers T. CT and MR imaging of congential abnormalities of the inner ear and internal auditory canal. Eur J Radiol. 2001 Nov;40(2): 94-104.

4. Yu KK, Mukherji S, CarrascoV, Pillsbury HC, Shores CG. Molecular genetic advances in semicircular canal abnormalities and sensorineural hearing loss: a report of 16 cases. Otolaryngol Head Neck Surg. 2003 Dec;129(6):637-46.

5. Sando I, Shibahara Y,Takagi A, Takahara T, Yamaguchi N. Frequency and localization of congenital anomalies of the middle and inner ears: a human temporal bone histopathological study. Int J Pediatr Otorhinolaryngol. 1988 Oct;16(1):1-22.

6. Wineland A, Menezes MD, Shimony JS, Shinawi MS, Hullar TE, Hirose K. Prevalence of semicircular canal hypoplasia in patients with CHARGE syndrome: 3C syndrome. JAMA Otolaryngol Head Neck Surg. 2017 Feb;143(2):168-77.

7. Johnson J, Lalwani AK. Sensorineural and conductive hearing loss associated with lateral semicircular canal malformation. Laryngoscope. 2000 Oct;110(10 Pt 1):1673-9.

8. Suehiro S, Sando I. Congenital anomalies of the inner ear: introducing a new classification of labyrinthine anomalies. Ann Otol Rhinol Laryngol Suppl. 1979 Jul-Aug;88(4 Pt 3 Suppl 59):1-24.

9. Sando I,TakaharaT, Ogawa A. Congenital anomalies of the inner ear. Ann Otol Rhinol Laryngol Suppl. 1984 Jul-Aug;112:110-8.

10. Phelps PD. Congenital lesions of the inner ear, demonstrated by tomography. Arch Otolaryngol. 1974 Jul;100(1):11-8.

11. Lim R, Brichta AM. Anatomical and physiological development of the human inner ear. Hear Res. 2016 Aug;338:9-21.

12. O'Rahilly R. The early development of the otic vesicle in staged human embryos. J Embryol Exp Morphol. 1963 Dec;11:741-55.

13. Yamashita K, Yoshiura T, Hiwatashi A, Tuvshinjargal D, Kamano H, Inoguchi T, et al. Sensorineural hearing loss: there is no correlation with isolated dysplasia of the lateral semi-circular canal on temporal bone CT.Acta Radiol. 2011 Mar;52(2):229-33.

14. Yukawa K, Horiguchi S, Suzuki M. Congenital inner ear malformations without sensorineural hearing loss. Auris Nasus Larynx. 2008 Mar;35(1):121-6.

15. Dallan I, Berrettini S, Neri E, Casani AP. Bilateral, isolated, lateral semicircular canal malformation without hearing loss. J Laryngol Otol. 2008 Aug;122(8):858-60.

16. Hadrys T, BraunT, Rinkwitz-Brandt S, Arnold HH, Bober E. Nkx5-1 controls semicircular canal formation in the mouse inner ear. Development. 1998 Jan;125(1):33-9.

17. McGarvie LA, Curthoys IS, MacDougall HG, Halmagyi GM. What does the head impulse test versus caloric dissociation reveal about vestibular dysfunction in Meniere's disease? Ann NYAcad Sci. 2015 Apr;1343:58-62.

18. Ozeki M, Kato Z, Sasai H, Kubota K, Funato M, Orii K, et al. Congenital inner ear malformations without sensorineural hearing loss in children. Int J Pediatr Otorhinolaryngol. 2009 Oct;73(10):1484-7.

19. Lopez I, Ishiyama G,Tang Y,Tokita J, Baloh RW, Ishiyama A. Regional estimates of hair cells and supporting cells in the human crista ampullaris. J Neurosci Res. 2005 Nov;82(3):421-31. 